\title{
An effective antibiotic cover for the prevention of endocarditis following dental and other post-operative bacteraemias ${ }^{1}$
}

\author{
OMAR KHAIRAT ${ }^{2}$ \\ From the Faculties of Medicine and Dentistry, Winnipeg, Canada
}

SYNOPSIS Pre- and post-extraction blood cultures were taken from 242 patients. The post-extraction ones were taken from 100 unpremedicated patients, from 42 with an erythromycin estolate cover, and from 100 patients after protection with pyrrolidino methyl tetracycline. The 100 post-extraction blood cultures from unpremedicated patients gave 64 positive results which yielded 155 strains, 88 of which were not aerobes.

One hundred and fifteen representative strains were tested for sensitivity to 22 antibiotics. Of the 42 patients who received the erythromycin orally, 16 yielded positive blood cultures of mixtures of aerobes and anaerobes and of the 100 given one intravenous injection of the tetracycline three only developed a bacteraemia of a single type of aerobe. The serum concentrations obtained with the tetracycline given intravenously were 15 to 20 times higher than the serum levels obtained with the erythromycin given orally.

There is a strong indication for using this kind of efficient antibiotic cover for dental extractions and other operative procedures known to be followed by a bacteraemia.

Bacterial endocarditis is in many cases the result of bacteraemia produced by operative procedures, among which is tooth extraction. It is stated that 25 to $50 \%$ of endocarditis patients had one or more teeth extracted some two months before the onset of the valvular ailment (Cates and Christie, 1951). Northrop and Crowley (1943) reported 23 such cases, and 94 other cases are on record by various other authors.

The bacteraemia of tooth extraction is transient, lasts about 10 minutes (Northrop and Crowley, 1943; Okell and Elliott, 1935), and the bacteria are most numerous in the blood stream within the first two minutes of their introduction into the circulation (Reichel, 1939). In persons with heart valves damaged by rheumatic fever, syphilis, or a congenital defect, the platelet-and-fibrin thrombi on the surface of the diseased valves trap some of the bacteraemic organisms, which then multiply and start an endocardial vegetation. The circulation time from the site of a tooth socket to an elbow vein is less than 18 seconds (Koch, 1922).

${ }^{1}$ This work was supported by a research grant from the National Research Council of Canada.

${ }^{2}$ Present temporary address: 911 West 64, Vancouver 14, B.C., Canada.

Received for publication 25 May 1966.
For an antibiotic cover during dental extraction various investigators tried sulphonamide compounds, penicillin, and other antibiotics, but all except one failed to isolate one single anaerobe in their unpremedicated post-extraction control blood cultures. Using sulphanilamide, Pressman and Bender (1944) obtained 7\% reduction (from $83 \%$ to $76 \%$ and Northrop and Crowley (1943) $5.4 \%$ reduction (from $15 \%$ to $9.6 \%$ ). With penicillin the reductions varied from $9 \%$ (Hirsch, Viveno, Merril, and Dowling, 1948) to $42 \%$ (Schirger, Martin, Royer, and Needham, 1960). With antibiotics other than penicillin the reductions were $61 \%$ (Khairat: the present work, the highest reduction ever obtained, in a series of 100 patients with 88 anaerobes isolated), $44 \%$ (Roth, Cavallaro, Parrott, and Celentano, 1950) with aureomycin orally, $28 \%$ (Bender, Pressman, and Tashman, 1958) using streptomycin sulphate intramuscularly, and $25 \%$ (Cooley and Haberman, 1957) with terramycin orally. The failure of some antibiotics completely to prevent the bacterial invasion of the blood stream after exodontia explains the occasional occurrence of endocarditis despite a penicillin cover.

In most of the published work no anaerobic culture was attempted. The present work completes the 
picture of the bacteraemic risks by determining the incidence of anaerobes as well as aerobes and by finding a safe antibiotic effective against both.

\section{METHODS}

THE BLOOD CULTURES This paper deals with a study of the incidence of positive blood cultures after tooth extraction in otherwise healthy patients; of the types of aerobic and anaerobic bacteria concerned; and the sensitivity of the freshly isolated bacteraemic strains to all the currently used antibiotics, and of the effect of premedication with two antibiotics on the incidence of positive blood cultures.

The incidence and nature of the bacteraemia was established in a series of pre- and post-extraction blood cultures from 100 unmedicated patients taken at random, regardless of the presence of pyorrhoea or of the number of teeth extracted. By sensitivity tests in vitro, two antibiotics were likely to be most active against the wide variety of bacterial species encountered in this condition. A second series of 142 patients, also taken at random, was tested: 42 after premedication with erythromycin estolate (Ilosone Lilly) orally, and 100 after premedication with pyrrolidino methyl tetracycline (Reverin Hoechst) intravenously.

For each of the pre- and the post-extraction blood cultures $30 \mathrm{ml}$. blood samples were taken by a modification of the technique described by Khairat (1939): three $7 \mathrm{ml}$. volumes of the blood were each added to $14 \mathrm{ml}$. of $0.05 \%$ Liquoid broth, $3 \mathrm{ml}$. into $6 \mathrm{ml}$. Liquoid broth for making three pour plates and $5 \mathrm{ml}$. for a sample of the patients' serum for antibiotic assay. The serum was removed from the clot after one hour and stored at $-20^{\circ} \mathrm{C}$. $A$ blood broth and one pour plate were incubated aerobically, another set in air containing $5 \% \mathrm{CO}_{2}$ (Khairat, 1964), and the third in an anaerobic jar fitted with a room temperature Deoxo catalyst (Khairat, 1965). The pour plates were made within three minutes of taking the blood sample.

The three blood broths were not subcultured before the sixth day even when macroscopic indications of growth appeared earlier, to allow slow-growing anaerobes to multiply. No colony was picked from the subcultured blood agar plates except under a stereo microscope, and no blood culture was discarded as sterile unless plate subcultures of the three blood broths showed no growth after five days' incubation in the three atmospheres.

TESTS in vitro of ANTIBIOTIC SENSITIVITY These were made for each of 115 of the freshly isolated bacteraemic strains, by flooding three blood agar plates with a young broth culture of the strain, 18 hours' culture for aerobic and $\mathrm{CO}_{2}$-dependent organisms, and 48 hours' culture for anaerobes, diluted $1: 5$. Excess culture fluid was removed and 15 minutes later commercially obtained sensitivity discs containing the lowest available concentration of antibiotic or other chemotherapeutic agent were applied, eight to each plate. The plates were incubated in the atmosphere most suitable for the organism. The 22 antibacterial substances used are listed in Table II. The 115 representative organisms tested were : 37 viridans streptococci including $\mathrm{CO}_{2}$-dependent ones, 18 anaerobic streptococci, a Str. faecalis, 37 corynebacteria includin $\overrightarrow{\mathrm{g}_{\text {t }}}$ non-aerobic corynebacteria, eight Bacteroides corroden $s^{+}$ strains never before isolated from the circulating blood (Wilson and Miles, 1964, p. 623), two Fusiformis strains two Bacteroides melaninogenicus, two other Bacteroides strains, three Neisseria pharyngis, one $N$. catarrhalis, tw@ Veillonella orbiculus, one Klebsiella aerogenes, and one्ल Micrococcus.

ASSAY OF ANTIBIOTIC IN SERUM For the assay of erythro mycin estolate and pyrrolidino methyl tetracycline' blood concentration, the patient's serum was seriallis diluted twofold in broth. A 16 hours' broth culture of Staph. aureus (A.T.C.C. 6538 P) was diluted $1 / 20$ and $0 . \overrightarrow{50}$ $\mathrm{ml}$. added to each $0.5 \mathrm{ml}$. of serum-broth mixture. The end-point of inhibition was recorded as the serum dilution totally inhibiting growth after 16 hours' incubation. This strain of Staph. aureus proved the most suitable tes? organism for both erythromycin estolate and pyrrolidinomethyl tetracycline, as judged by previous tests with it in parallel with Sarcina lutea (Micrococcus luteus) (A.T.C.C. 9341), B. subtilis (A.T.C.C. 6633), B. cereus (A.T.C.C 11778), and Str. pyogenes (A.T.C.C. 8668).

\section{RESULTS}

BACTERAEMIA IN UNMEDICATED PATIENTS All but one of the 242 pre-extraction blood cultures were steriles The one exception yielded an albus type of staphylo $\bar{\partial}$ coccus, which, since the pour-plates indicated anf average of 40 colonies per millilitre of circulating $D$ blood, was clearly not a contaminant. Indeed Staph. albus (nine colonies per ml.) was isolated from the same patient 11 days later from a pre-extraction? blood culture.

From the 100 unpremedicated patients, the post extraction blood cultures were positive in 64 , yielding a total of 155 strains (Table I). Eighty-eight of the strains were non-aerobes and 67 were aerobes (Khairat, 1966). The non-aerobes included five strictly $\mathrm{CO}_{2}$-dependent organisms, some of them $\mathrm{CO}_{2}$-dependent viridans streptococci, 46 obligate anerobes, and 37 which grew both in hydrogen and in air containing $5 \% \mathrm{CO}_{2}$. One third of the 64 positive blood cultures grew one type of organism N and the maximum number of different types of bacteria growing in one blood culture was seven Half the aerobes were viridans streptococci; some of the anerobic streptococci isolated produced black colonies. The degree of bacteraemia was such that ife $75 \%$ of the positive cases the pour plates indicated that the circulating blood contained one colony per millilitre.

Neither 'rocking' (wrenching) during teeth extrac-융 tion, i.e., excessive trauma, nor epinephrine in the? local anaesthetic had any effect on the number of positive blood cultures obtained. 
TABLE I

THE SPECIES DISTRIBUTION OF 115 POST-EXTRACTION STRAINS FROM 100 UNPREMEDICATED PATIENTS AND THEIR GASEOUS GROWTH REQUIREMENTS

Strain

Growth

Total

\begin{tabular}{llll}
\hline $\begin{array}{l}\text { Aerobically and in } \\
\text { Other Atmospheres }\end{array}$ & $\begin{array}{l}\text { Only in Air } \\
\text { containing } 5 \% \mathrm{CO}_{2}\end{array}$ & Only Anaerobically & $\begin{array}{l}\text { Only Anaerobically } \\
\text { and in Air Containing } \\
5 \% \mathrm{CO}_{2}\end{array}$
\end{tabular}

Viridans streptococci

Anaerobic streptococci

Black colonied anaerobic streptococci

Str. pyogenes

Str. faecalis

Corynebacteria

Bacteroides corrodens

Fusiformis organisms

Bacteroides melaninogenicus

Other Bacteroides species

Neisseria pharyngis

N. catarrhalis

Veillonella orbiculus

Staphylococcus aureus

Staph. albus

A Gram-positive Micrococcus

Klebsiella aerogenes

Totals

The significant number of $\mathrm{CO}_{2}$-dependent and anaerobic bacteria isolated emphasizes the importance of making blood cultures (and indeed all cultures) in triplicate and incubating not only in air, but also in the other two atmospheres used (Wilson and Miles, 1964).

ANTIBIOTIC SENSITIVITY TESTS The test in vitro of 115 freshly isolated post-extraction bacteraemic strains with 22 antibiotics and antibacterial chemotherapeutic substances indicated four antibiotics that inhibited over $85 \%$ of the strains (Table II). Excluding the two furadantoins, the four were erythromycin estolate, demethyl chlor-tetracycline (Declomycin or Ledermycin, Lederle), tetracycline and ampicillin (Penbritin Beecham) as shown in Table II. Of these, erythromycin estolate and tetracycline in the form of the pyrrolidino methyl compound were selected for clinical trial.

The broad-spectrum penicillin ampicillin was not considered further because of the frequency of anaphylactic reactions associated with the use of penicillins. Erythromycin estolate was chosen for clinical testing not only because it gave good results in vitro (Table II) but because blood concentrations (in the region of 1 to $2 \mu \mathrm{g} . / \mathrm{ml}$.) are attainable one hour or even 30 minutes after administration, a feature of some importance for the controlled premedication of dental out-patients with little attendant risk of the development of resistant strains

$\begin{array}{rrrr}1 & - & 9 & 44 \\ = & 13 & 7 & 20 \\ - & 4 & - & 4 \\ 3 & - & - & 1 \\ -1 & 2 & 16 & 42 \\ - & 16 & - & 16 \\ - & 3 & - & 9 \\ - & 2 & - & 4 \\ - & 4 & - & 3 \\ - & - & - & 1 \\ - & 2 & - & 2 \\ - & - & - & 1 \\ - & - & - & 1 \\ 5 & - & 37 & 155\end{array}$

TABLE II

SENSITIVITY OF 115 FRESHLY-ISOLATED POST-EXTRACTION BACTERAEMIA STRAINS TO 22 ANTIBIOTICS AND ANTIBACTERIAL COMPOUNDS

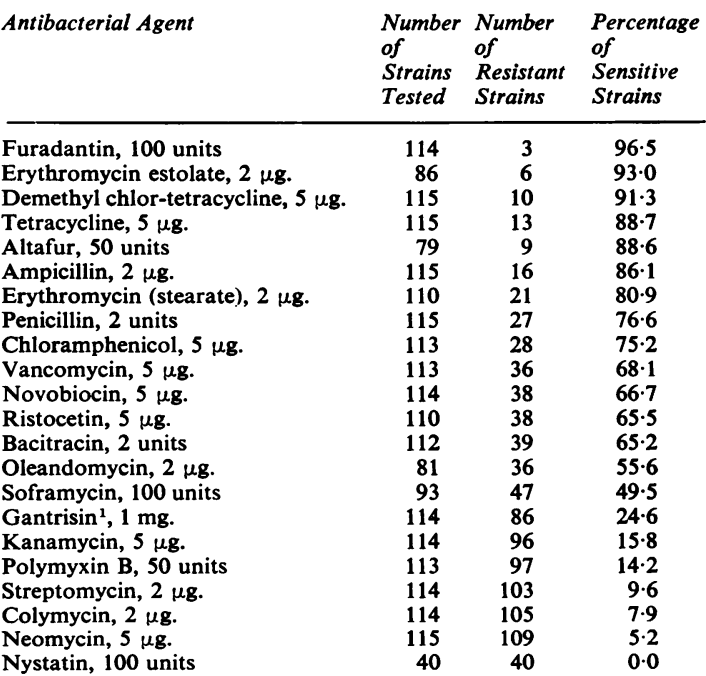

${ }^{1}$ Representing all the sulphonamides.

(Garrod and Waterworth, 1962). The furadantoins and Altafur were included only for their bacteriological interest, being compounds unsuitable for use for the treatment of bacteraemia. Pyrrolidino methyl 
tetracycline was chosen because it had been in use since 1957 without any recorded toxic sequelae, including thrombophlebitis.

ANTIBIOTIC PROPHYLAXIS AGAINST BACTERAEMIA The results of premedication with erythromycin estolate and pyrrolidino methyl tetracycline are summarized in Table III.

\section{TABLE III}

CLINICAL TRIAL OF PREMEDICATION WITH TWO ANTIBIOTIC COVERS

\begin{tabular}{llll} 
Antibiotic Cover & $\begin{array}{l}\text { Dose } \\
\text { (mg.) }\end{array}$ & $\begin{array}{l}\text { Timing (min.) } \\
\text { of }\end{array}$ & $\begin{array}{l}\text { Number } \\
\text { of }\end{array}$ \\
$\begin{array}{l}\text { Premedication } \\
\text { before } \\
\text { Extraction }\end{array}$ & $\begin{array}{l}\text { Number } \\
\text { of Positive } \\
\text { Blood } \\
\text { Cultures }\end{array}$ \\
\hline
\end{tabular}

\begin{tabular}{|c|c|c|c|c|}
\hline Nil. (controls) & - & - & 100 & 64 \\
\hline $\begin{array}{l}\text { Erythromycin } \\
\text { estolate, } \\
\text { orally }\end{array}$ & $\left\{\begin{array}{r}250 \\
500 \\
500 \\
500 \\
1000\end{array}\right.$ & $\begin{array}{r}90 \\
90 \\
120 \\
240 \\
240\end{array}$ & $\begin{array}{r}16 \\
9 \\
2 \\
6 \\
9\end{array}$ & $\begin{array}{l}6 \\
3 \\
2 \\
2 \\
3\end{array}$ \\
\hline $\begin{array}{l}\text { Pyrrolidino-methyl } \\
\text { tetracycline, } \\
\text { intravenously }\end{array}$ & 275 & 3 & 100 & 3 \\
\hline
\end{tabular}

Erythromycin estolate With one $250 \mathrm{mg}$. erythromycin estolate capsule orally, six cultures were positive, yielding different combinations of anaerobic and viridans streptococci, corynebacteria, N.pharyngis and Bacteroides melaninogenicus. Neither a twofold nor a fourfold increase of the dose, nor an increase up to four hours in the period for absorption of the drug, improved on this result. The dose was changed as soon as positive blood cultures were obtained. The bacteria in the 10 remaining positive blood cultures included those named above and also Fusiformis and Veillonella spp. The dose could not be further increased for fear of toxic effects. Thus erythromycin estolate failed as a certain antibiotic cover, protecting only 26 of the 42 patients: $38 \%$ of the cultures were positive, a confidence limit of 23.5 to $54.3 \%$ positive.

The strains isolated from the 16 failures were all sensitive in vitro to $2 \mu \mathrm{g}$. erythromycin estolate discs, i.e., they were very sensitive to it. But even after the full $1 \mathrm{~g}$. dose given four hours before extraction, the Staph. aureus inhibition titre of the serum varied from $1 / 8$ to $1 / 32$, an average of $1 / 20$. A serum titre of $1 / 32$ is equivalent to $1.0 \mu \mathrm{g} . / \mathrm{ml}$. of Ilosone four hours after a dose of $250 \mathrm{mg}$. (Perry, Hall, and Kirby, 1958).

It was perhaps too much to expect that a concentration of drug sufficient to destroy a bacteraemic infection could be obtained in the blood by giving a single oral dose. The same applies to intramuscular injection and to slow intravenous infusion drip.
Pyrrolidino methyl tetracycline Effective concentrations would clearly be more readily obtained b $\overrightarrow{F_{5}}$ intravenous administration of an antibiotic in 8 concentrated form given immediately before tootle extraction. Accordingly pre-operative injections of: $275 \mathrm{mg}$. pyrrolidino methyl tetracycline dissolved ic $10 \mathrm{ml}$. sterile distilled pyrogen-free water were given to 100 patients. The injections were made verys slowly, in two to three minutes, and as far as possible the tooth or teeth were extracted immediately after $=$ wards. The serum titre of pyrrolidino methyl tetra cycline in samples taken at the time of blood cultures ranged between $1 / 256$ and $1 / 512$, corresponding to blood concentration of 18 to $25 \mu \mathrm{g}$./ml. (Wagner. 1964) which was 15 to 20 times the concentratiog achieved after the oral erythromycin treatment. The bacteriological results were striking: only three of the 100 patients gave positive blood cultures, each due to. a single type of bacterium, viridans streptococci in two cases, and a corynebacterium in one case. It i noteworthy that these were all aerobic species. This was a reduction in the number of the bacteraemi strains isolated, from 57 aerobes plus 88 non-aerobes (a total of 155) to three aerobes, and a reduction im the positive blood cultures of $61 \%$ (from $64 \%$ to $3 \%$ The two viridans strains were resistant to $5 \mu \mathrm{g}$ but not to $30 \mu \mathrm{g}$. tetracycline discs (there are n£ Reverin discs). The corynebacterium was sensitive to both concentrations.

Of the 100 patients receiving a pyrrolidino methy tetracycline cover, none manifested any side effects except that about half of them experienced a taste of soap or ether during the injection.

\section{DISCUSSION}

The corynebacteria isolated from the unpremedicate patients were not contaminants, for none of the pre? extraction blood samples, taken from the same patients two or three minutes before the posf extraction ones, yielded any organisms. All samples were taken by the author, using exactly the same. technique.

Though no antibiotic inactivator was incorporated in the blood culture medium, since none is know for the erythromycins or for the tetracyclines, one at the two antibiotics used failed in its series of bloog cultures whereas the other did not.

In testing 115 representative strains against 28 antibiotics to determine their sensitivity precisely, the results with the disc method only give a rough guide to the sort of antibiotic that might be used, ang despite the large number of strains tested (Table II the same applies to the percentage differences betwee the closely allied drugs, especially since no accurateg 
assayed control for each disc (obtainable from each manufacturer) was put.

As to the large number of anaerobes isolated in the present work, this might explain why many of the endocarditis patients with certain clinical signs repeatedly give negative (aerobic) blood cultures. The cause is undoubtedly lack of proper anaerobic culturing technique.

Although a few of the 22 antibacterial drugs tested are intended for topical use only, e.g., soframycin, or are mainly active against fungi, e.g., nystatin, they were nevertheless tested since there is little recorded information about sensitivity of the various aerobic and anaerobic dental and oral flora to the antibiotics in common use. It should be stressed that most of the dental bacteraemia organisms isolated were Gram positive, and, as was to be expected, were not susceptible to antibiotics active mainly on Gram-negative bacteria.

The explanation of failure in the three cases is not surprising because even at bactericidal concentrations a few organisms commonly persist and on incubation the drug will degenerate to less than the bacteriostatic level which will allow growth. From a practical point of view this does not matter because in the patient natural antibacterial mechanisms would be at work to demolish the few persisting organisms, whereas in the culture such mechanisms are inactive.

The pour plates of these patients showed very low counts: one colony per millilitre in two of the cases and no colonies in the third. Low pour plate-counts were also met with in the 16 erythromycin estolate failures. However, the argument that because there were few colonies in the pour plates the original number released into the blood was low is not valid, because as the blood contained 18 to $25 \mu \mathrm{g}$. $/ \mathrm{ml}$. of the tetracycline, the concentration in the plates (assuming $15 \mathrm{ml}$. medium per plate) was between 1.2 and $1.6 \mu \mathrm{g} . / \mathrm{ml}$. which may have been high enough to inhibit primary growth, allowing just a few comparatively resistant colonies to appear. However, without the use of any antibiotic cover the degree of bacteraemia in 64 positive post-extraction blood cultures was very low: one colony per millilitre of the circulating blood in $75 \%$ of these positive cases (Khairat, 1966). It is thus obvious that there cannot have been a large number of highly resistant organisms in the blood in these three cases.

The sensitivity in vitro of the 115 freshly isolated bacteraemia strains to both antibiotics was almost similar, but the 20 times higher blood levels of the intravenous pyrrolidino methyl tetracycline over the oral erythromycin estolate explains why the first succeeded and the second failed in combatting the bacteraemia. During the 10 minutes following an injection of $275 \mathrm{mg}$. pyrrolidino methyl tetracycline (which is the usual duration of the transient bacteraemia) the average blood level starts at 27 to 30 $\mu \mathrm{g} . / \mathrm{ml}$. and ends with 14 to $19 \mu \mathrm{g}$. $/ \mathrm{ml}$. (Wagner, 1964). This concentration at the end of 10 minutes is still 10 to 15 times the concentrations attained with oral antibiotics. A concentrated intravenous antibiotic, such as pyrrolidino methyl tetracycline, is certainly more likely to kill the bacteria as soon as they are released into the circulation and before they establish a foothold on the heart valves, or at least more likely to damage the bacteria within the 10 minute period of bacteraemia. It must be realized however, that pyrrolidino methyl tetracycline ster:lized blood cultures but that it might not necessarily sterilize a bacteraemia. However, it can be properly concluded that pyrrolidino methyl tetracycline was active against anaerobes as well as aerobes and that, in so far as one can argue from the results obtained in the present work, a substance of this class would be a good choice in any attempt to give cover before operative procedures, using the intravenous route, for a rapidly attained high concentration of circulating antibiotic.

Bender et al. (1958) administered $1 \mathrm{~g}$. chloramphenicol in a single intravenous dose to 32 patients half an hour before extraction and obtained a reduction from $85 \%$ to $22 \%$ positive blood cultures though they isolated no anaerobes in their work. They did not incorporate an inactivator in their blood culture medium as there is no inactivator known for chloramphenicol.

Although Roth et al. (1950), who used aureomycin orally in a small group of 25 patients, claimed a reduction from $64 \%$ to $4 \%$ (the $4 \%$ figure ought to be corrected to $20 \%$ because they dropped four positive blood cultures which yielded albus staphylococci and 'diphtheroids'), counting these as contaminants even though the organisms grew in both the blood broths and the pour plates, and in addition the pre-extraction samples from all 25 unpremedicated controls were free from contaminants.

With the exception of the work of Francis, De Vries, Soomsawasdi, and Platonow (1962), who isolated 30 anaerobic strains though they attained a reduction of only $28 \%$, from $36 \%$ to $8 \%$, in a series of 25 patients given penicillin, none of the other workers who tested an antibacterial cover record any cultivation of anaerobes. Their recorded reductions should therefore be further drastically lowered, for it would be grossly unfair to compare their reductions, which varied from $5.4 \%$ to $44 \%$, with the $61 \%$ reduction in the present work where 88 non-aerobes were isolated in addition to 76 aerobes.

As to whether an effective antibiotic cover such as pyrrolidino methyl tetracycline should be used for all dental extractions, opinions differ. All agree that 
there is a good case for its use in patients known to have had rheumatic fever, and certainly in those with signs of valvular disease. There is a strong case for using an effective antibiotic cover as a precautionary measure before every extraction and also before other operative procedures known to be followed by a bacteraemia, such as tonsillectomy, since not every patient remembers if he or she has had an attack of rheumatic fever in childhood, and we should not forget that some affected valves are murmurless; the preparation and injection of the antibiotic do not take more than four minutes; that this intravenous antibiotic gave negative blood cultures in $97 \%$ of the cases immediately following the extractions when the bacteraemia was at its height; and because in addition to its efficacy the blood concentration of pyrrolidino methyl tetracycline remains high long enough to deal with bacteria that might settle on the valves (Wagner, 1964). McGregor (1962) favours this course, at least 'to protect murmurless valves'.

I am indebted to Mrs. Lára Khairat, B.A., B.S.W. for performing most of the antibiotic sensitivity tests and to Mrs. Doris Pritchard, B.A., B.L.S. for help with the references.

The pyrrolidino methyl tetracycline used in this work was supplied as Reverin through A. B. Coté, B.Pharm., of Hoechst, and the erythromycin estolate, as Ilosone through Don F. Forsyth, B.Pharm., of Eli Lilly.
My thanks are also due to Professor Sir Ashley Miles F.R.S., for his advice and helpful criticism.

\section{REFERENCES}

Bender, I. B., Pressman, R. S., and Tashman, S. G. (1958). J. Amer dent. Ass., 57, 54.

Cates, J. E., and Christie, R. V. (1951), Ouart. J. Med., 20, 93

Cooley, F. H., and Haberman, S. (1957). J. dent. Res., 36, 294.

Francis, L. E., de Vries, J. A., Soomsawasdi, P., and Platonow, M. (1962). J. Canad. dent. Ass., 28, 683.

Garrod, L. P., and Waterworth, P. M. (1962). Brit. Heart J., 24, 39.'

Hirsch, H. L., Vivino, J. J., Merril, A., and Dowling, H. F. (1948) Arch. intern. Med., 81, 868.

Khairat O (1939). A Study of Bacteraemia in the Human Subject and of the Technique of Blood Culture. Ph.D. Thesis, Londoff University.

_ (1964). Canad. J. Microbiol., 10, 499.

(1965). Amer. J. clin. Path., 43, 596.

(1966). J. dent. Res., 45, 1191.

Koch, E. (1922). Dtsch. Arch. klin. Med., 27, 40.

MacGregor, G. A. (1962). Lancet, 2, 993.

Northrop, P. M., and Crowley, M. C. (1943). J. oral Surg., 1, 19.

Okell, C. C., and Elliott, S. D. (1935). Lancet, 2, 869.

Perry, D. M., Hall, G. A., and Kirby, W. M. M. (1958-59). AntibiotAnn., 376 (Fig. 2), 378 and 380.

Pressman, R. S., and Bender, I. B. (1944). Arch. intern. Med., 74k 346.

Reichel, H. A. (1939). Proc. Mayo Clin., 14, 138

Roth, O., Cavallaro, A. L., Parrott, R. H., and Celentano, R. (1950) Arch intern. Med., 86, 498

Schirger, A., Martin, W. J., Royer, R. Q., and Needham, G. M(1960). J. Lab. clin. Med., 55, 376.

Wagner, W. H. (1964). In Proceedings IIIrd International Congress of Chemotherapy, Stuttgart, 1963, p. 1716. Thieme, Stuttgart.

Wilson, G. S., and Miles, A. A., eds. (1964). Topley and Wilsor Principles of Bacteriology and Immunity 5th ed., pp. 1789 1790. Edward Arnold, London. 